\title{
Evaluation of protective efficacy induced by virus-like particles containing a Trichinella spiralis excretory-secretory (ES) protein in mice
}

\author{
Su-Hwa Lee ${ }^{1,2}$, Sang-Soo Kim², Dong-Hun Lee ${ }^{1,2}$, Ah-Ra Kim ${ }^{1,2}$ and Fu-Shi Quan²*
}

\begin{abstract}
Background: The frequent outbreaks of human trichinellosis globally underscore the need to develop effective vaccine. We hypothesized that a novel vaccine could improve vaccine efficacy against Trichinella spiralis.

Methods: In this study, we developed virus-like particles (VLPS) containing the $53 \mathrm{KDa}$ excretory/secretory (ES) protein of T. spiralis and the influenza matrix protein 1 (M1) as a core protein, and investigated the protective efficacy of the VLPs alone or with cholera toxin (CT) in a mouse model.

Results: Intramuscular immunization induced T. spiralis-specific IgG, IgG1 and IgG2a antibody responses before and after challenge infections in the sera. These antibody responses were significantly enhanced in mice immunized with adjuvanted VLPs. Upon challenge infection, vaccinated mice showed significantly reduced worm burden in the diaphragm. Protective immune responses and efficacy of protection were significantly improved by immunization with VLPs together with CT adjuvant.
\end{abstract}

Conclusions: Our results are informative for a better understanding of the protective immunity induced by $T$. spiralis VLPS, and will provide insight into designing safe and effective vaccines.

Keywords: Trichinella spiralis, Virus-like particle, Cholera toxin, Vaccine, Protection

\section{Background}

Trichinellosis is a parasitic infection caused by Trichinella spiralis, which is a serious parasitic zoonosis and a globally endemic disease [1-3]. Human infection is commonly the result of eating raw or undercooked meat containing Trichinella larvae. Pork and its products are closely associated with outbreaks of human trichinellosis. The global prevalence of trichinellosis is difficult to evaluate, but as many as 11 million people may be infected. The frequent outbreaks of human trichinellosis globally underscore the need to develop an effective vaccine [4-6]. The development of vaccines would have significant impact towards the ultimate goal of disease elimination $[7,8]$.

\footnotetext{
* Correspondence: fsquan@khu.ac.kr

${ }^{2}$ Department of Medical Zoology, Kyung Hee University School of Medicine Seoul, South Korea

Full list of author information is available at the end of the article
}

Natural parasite extracts, recombinant protein, synthetic peptides, attenuated phage display and genetic immunization have been used for vaccine studies. Radiation, ultraviolet-attenuated or DNA-plasmid vaccines for Trichinella spiralis were found to be highly protective in experimental animals. However, such vaccines are not well suited for field use [5, 6, 9-11].

Recombinant vaccines based on virus-like particles (VLPs) or nanoparticles have displayed promising safety and efficacy in preclinical and clinical studies [12]. Virus-like particles resemble viruses, but do not contain any viral genetic material. Thus, they do not replicate, having advantages for safety [13-15]. VLPs contain repetitive high density displays of viral surface proteins, which present conformational epitopes that can elicit strong cellular and humoral immune responses [12].

Immunization with $T$. spiralis ES protein elicits a robust immune response, and resulted in complete protection 
against infective larvae [16]. The $53 \mathrm{kDa}$ protein of T. spiralis has been used as an immunomodulatory protein for treating inflammatory disease such as bowel diseases [17]. The $T$. spiralis $53 \mathrm{kDa}$ protein is reported to be a novel serological marker and vaccine candidate [18]. The 53$\mathrm{kDa}$ recombinant proteins provide early and speciesspecific antibody responses in mice infected with $T$. spiralis [19]. However, there is no report on vaccine efficacy of $T$. spiralis $53 \mathrm{kDa}$ against challenge infection. Thus, we were interested to test the hypothesis that $T$. spiralis $53 \mathrm{kDa}$ protein in virus-like nanoparticle form could be an important immunogen which could induce humoral and/or cellular immunity.

To the best of our knowledge, in this study for the first time VLPs derived from parasite $T$. spiralis were produced. These novel VLPs containing T. spiralis $53 \mathrm{kDa}$ protein and influenza matrix M1 as a core protein were evaluated as a potential vaccine. We also investigated the effect of CT as an adjuvant for the VLP vaccine.

\section{Methods}

Parasite, virus, cells and antibodies

Korean isolate of $T$. spiralis was obtained from specific pathogen-free female, inbred Sprague-Dawley (SD) rats, aged 8 weeks, maintained by serial oral passage. Influenza virus (A/PR/8/34) was used to infect MDCK cells. Spodoptera frugiperda Sf9 cells were maintained in suspension in serum-free SF900II medium (Invitrogen, Carlsbad, USA) at $27{ }^{\circ} \mathrm{C}$ in spinner flasks at a speed of 130 to $140 \mathrm{rpm}$. Horseradish peroxidase (HRP)-conjugated goat anti-mouse immunoglobulin A (IgA) and G (IgG), IgG1 and IgG2a were purchased from Southern Biotech (Birmingham, USA).

\section{Preparation of $T$. spiralis antigen}

Trichinella spiralis excretory/secretory (ES) product was produced as described previously [20-22]. Larvae of $T$. spiralis were isolated from rat muscle tissue by artificial digestion and washed. Clean larvae were incubated in a $\mathrm{CO}_{2}$ incubator for $24 \mathrm{~h}$ at $37^{\circ} \mathrm{C}$ in Petri dish containing RPMI-1640 culture medium without FBS. The culture supernatants were collected by centrifugation. The supernatant was dialyzed and lyophilized. The protein concentration was determined by QuantiPro BCA Assay Kit (Sigma-Aldrich, St Louis, USA). Trichinella spiralis ES products were identified by SDS-PAGE (Additional file 1: Figure S1) and stored at $-70{ }^{\circ} \mathrm{C}$ until use.

\section{Construction of rBV expressing $T$. spiralis (T653K) and influenza M1}

Total RNA was extracted from the $T$. spiralis larvae using RNeasy Mini Kit (Qiagen, Valencia, USA). The RNA was reverse transcribed to cDNA using the Prime Script 1st strand cDNA synthesis kit according to the manufacturer's instructions (Takara, Otsu, Japan). The cDNA was used as a template to amplify the complete coding sequence of $\mathrm{T} 653 \mathrm{~K}$ by polymerase chain reaction (PCR). The primers were designed according to the nucleotide sequence of T653K in GenBank (accession number: DQ399914): forward (5'-AAA GAA TTC ACC ATG TTC AGC ATC ACA TTA AA-3') and reverse (5' ${ }^{\prime}$ TTA CTC GAG TTA GAA CAA CAA CTG TAG T-3') with EcoRI and Xhol restriction enzyme sites. The PCR product was inserted into the pFastBac vector (Invitrogen, Carlsbad, USA). For M1 gene cloning, $\mathrm{A} / \mathrm{PR} / 8 / 34$ virus was inoculated into MDCK cells and total viral RNA was extracted using an RNeasy Mini kit (Qiagen, Valencia, USA). Reverse transcription (RT) and PCR were performed on extracted viral RNA using the One-Step RT-PCR system (Invitrogen, Carlsbad, USA) with gene specific oligonucleotide primers. The following primer pairs were used forward, M1 (5' - TCC CCC GGG CCA CCA TGA GCC TTC TGA CCG AGG TC -3'); reverse, M1 (5' - TTA CTT CTA GAT TAC TTG AAC CGT TGC ATC TG -3') with SmaI and XbaI restriction enzyme sites. Following RT-PCR, a cDNA fragment containing the $\mathrm{M} 1$ gene was cloned into the pFastBac vector (Invitrogen, Carlsbad, USA). The recombinant plasmid was transformed into E. coli DH5alpha and transferred into a DH10-Bac. The nucleotide sequences of M1 (accession number: EF467824) and T653K (accession number; DQ399914.1) genes in the pFastBac vector were confirmed by DNA sequencing.

\section{Production of recombinant baculovirus and VLPs}

Transfections of DNA containing the above genes were accomplished using cellfectin II (Invitrogen, Carlsbad, USA) with Sf9 cells as recommended by the manufacturer, followed by transformation of pFastBac containing T653K or influenza M1 with white/blue screening. The rBVs were derived by using a Bac-to-Bac expression system (Invitrogen, Carlsbad, USA). To produce VLPs containing T653K and M1, Sf9 cells were co-infected with rBVs expressing T653Kand M1. Cell culture supernatants were collected on day 2 or 3 post-infection, cleared by centrifugation at $6,000 \mathrm{rpm}$ for $30 \mathrm{~min}$ at $4{ }^{\circ} \mathrm{C}$ to remove cells. VLPs in the supernatants were pelleted by high-speed centrifugation $(45,000 \times g$ for $30 \mathrm{~min})$. The sedimented particles were resuspended in phosphatebuffered saline (PBS) at $4{ }^{\circ} \mathrm{C}$ overnight and further purified through a 20-30-60\% discontinuous sucrose gradient at $45,000 \times g$ for $1 \mathrm{~h}$ at $4{ }^{\circ} \mathrm{C}$. The VLP bands were collected and pelleted by high-speed centrifugation (45,000 $\times g$ for $30 \mathrm{~min}$ ). VLPs were resuspended in $500 \mu \mathrm{l}$ phosphate-buffered saline (PBS) overnight at $4{ }^{\circ} \mathrm{C}$ and protein concentration was determined using a QuantiPro BCA Assay Kit (Sigma-Aldrich, St Louis, USA). 


\section{Characterization of VLPs}

VLPs were characterized by Western blots and electron microscopy. For Western blot analysis, mouse serum was used to probe T653K protein. Serum was from $\mathrm{BALB} / \mathrm{c}$ mice infected with the $T$. spiralis Korean isolate. Serum was collected at week 4 after infection. Monoclonal mouse anti-M1 antibody was used to determine M1 protein content. For electron microscopy, negative staining of VLPs was performed followed by transmission electron microscopy (Tecnai G2 spirit), (FEI, Hillsboro, USA).

\section{VLP immunization schedule and challenge infection}

Female, BALB/c mice (6-8 week-old) were divided into 4 groups; naïve control, $T$. spiralis infection control (TS control), T653K VLP and T653K VLP/CT. Mice were intramuscularly immunized with T653K VLPs with or without CT $(25 \mu \mathrm{g}$ VLPs/mouse, $2 \mu \mathrm{g}$ CT/mouse, 10 mice in each group). All experimental groups were vaccinated at weeks 0 and 4 . Four weeks after the last immunization, 10 mice of each group were challenged orally with $100 \mathrm{~T}$. spiralis (Korea isolate) larvae per mouse. Mice were sacrificed 6 weeks after challenge infection, larvae were collected from the mouse diaphragm and counted after the diaphragm was digested with artificial digestion solution ( $1 \% \mathrm{HCl}-1.5 \%$ pepsin). The rate of reduction in larval burden was calculated according to the recovered larvae per gram muscle. Blood was collected from the retro-orbital plexus on week $0,1,5,8$ before challenge and on week 1, 4 and 6 after challenge infection. Sera were separated and stored at $-20{ }^{\circ} \mathrm{C}$ until analyzed for specific antibodies. All animal experiments and husbandry involved in these studies were conducted under the guidelines of the Kyung Hee University IACUC. Kyung Hee IACUC operates under the National Veterinary Research and Quarantine Service (NVRQS) and regulations of the World Organization for Animal Health (WOAH).

\section{Evaluation of humoral immune responses}

Sera from experimental mice were used in an enzymelinked immunosorbent assay (ELISA) to measure the levels of IgG, IgG1 and IgG2a against T. spiralis antigen. 96 well flat-immunoplate (SPL) were coated overnight at $4{ }^{\circ} \mathrm{C}$ with $100 \mu \mathrm{l}$ of $T$. spiralis antigen at a concentration of $4 \mu \mathrm{g} / \mathrm{ml}$ in $0.05 \mathrm{M}$ carbonate bicarbonate buffer (pH 9.6) per well. Serum samples diluted (1:100) in PBST $(100 \mu \mathrm{l} /$ well $)$ were then added in duplicate.

\section{Cytokine analysis}

Individual mouse spleens were collected 2.5 months after immunization from the immunized and naive groups. Single-cell suspensions were prepared from each spleen. Cells were incubated in 96-well flat culture plates for 2 days at $37{ }^{\circ} \mathrm{C}$ in the presence of $5 \% \mathrm{CO}_{2}$. Cells in
$100 \mu \mathrm{l}$ of RPMI-1640 were stimulated with $100 \mu \mathrm{l}$ of $2 \mu \mathrm{g} / \mathrm{ml} \mathrm{T}$. spiralis ES Ag. For the cytokine assay, supernatants of spleen cell cultures were collected from each well by separation and stored at $-20{ }^{\circ} \mathrm{C}$ until use. OptEIA sets (BD Bioscience, San Jose, CA, USA) were used to determine the concentration of interferon-gamma (IFN- $\gamma$ ), interleukin (IL)-2, IL-4 and IL-10 in culture supernatants following the manufacturer's procedures.

\section{Statistics}

All parameters were recorded for individuals within all groups. Statistical comparisons of data were carried out using the Kruskal-Wallis test and Paired t-test of PC-SAS 9.3. A $P$-value $<0.05$ was considered to be significant.

\section{Results}

\section{Generation of constructs}

The T653K gene from T. spiralis Korean isotype was amplified by PCR and the influenza M1 gene was amplified by RT-PCR with primers containing restriction enzyme sites (Fig. 1a, c). Genes were cloned into pFastBac vectors, and insertion of T653K and M1 in pFastBac expressing vectors was confirmed by cutting with restriction enzyme sites, T653K: BamHI and XbaI, M1: SmaI and XbaI (Fig. 1b, d). The nucleotide sequences of the T653K and M1 genes were found to be identical to the previously published sequences by DNA sequencing.

\section{Production of VLPs}

VLPs containing influenza T653K and M1 were produced as described in Methods. VLPs were harvested from the culture supernatants of $\mathrm{Sf} 9$ cells co-infected with two individual rBVs that express either T653K or M1. The size and morphology of VLPs containing T653K and M1 were examined by electron microscopy. The morphology of VLPs resembles the shape of influenza virus with spikes on their surfaces (Fig. 2a). The particle sizes ranged from approximately 40 to $120 \mathrm{~nm}$. These results show that VLPs expressing T653K and M1 were generated. The incorporation of T653K and M1 into VLPs was confirmed by western blot using antibodies described in the methods (Fig. 2b).

\section{Humoral immune responses induced by immunization with T653k VLPs}

Mouse sera collected at different time points after immunization were used to measure levels of specific anti-T. spiralis IgG and subtype (IgG1 and IgG2a) antibodies (Fig. 3a). Higher levels of T. spiralis-specific IgG were found in mice immunized with T653K VLPs with or without CT compared to naïve controls on week $0,1,5$ and 8, where T653K VLPs with CT showed better T. spiralis-specific IgG response than T653K VLP without CT, indicating $\mathrm{CT}$ was an effective adjuvant (Fig. $3 \mathrm{~b} ; \chi^{2}=7.2$, 


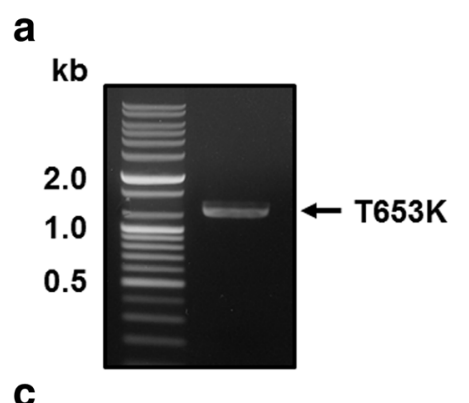

C

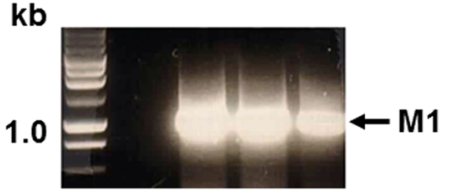

b

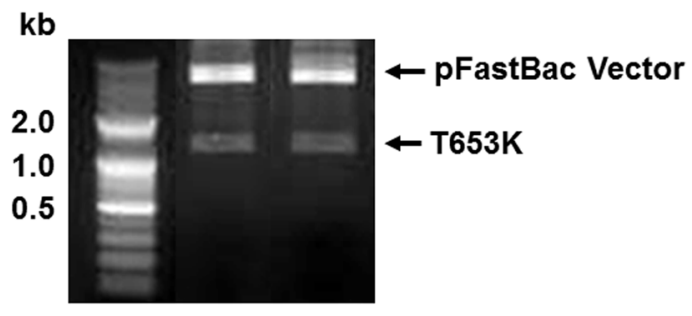

d

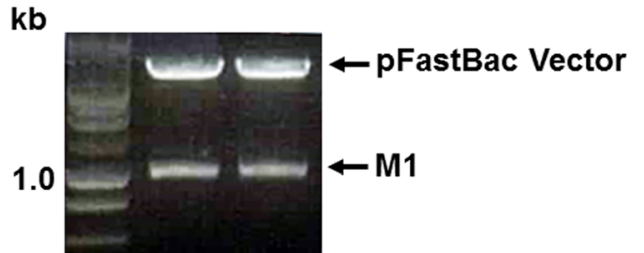

Fig. 1 PCR identification of T653K and M1 genes and recombinant plasmids pFastBac-T653K and pFastBac-M1 digested. The T. spiralis T653K gene was PCR-amplified from cDNA synthesized using a Prime Script $1^{\text {st }}$ Strain cDNA Synthesis Kit using total RNA extracted from $T$. spiralis Korean isotype (a). Influenza M1 gene was PCR amplified fromtotal RNA extracted from influenza virus (A/PR/8/34) (c). The T. spiralis T653K gene and influenza M1 gene were cloned into pFastBac with EcoRl/Xhol and Saml/Xbal enzymes, respectively, resulting in T653K plasmid (b) and M1 plasmid (d). Marker: DNA marker; size of T653K: 1,239 bp; size of M1: 1,027 bp

$d f=2, \quad P=0.0273)$. Higher levels of $T$. spiralis-specific IgG1 and IgG2a antibody responses were also detected in mice immunized with T653K VLPs with CT on week $0,1,5$ and 8 after immunization compared to VLPs without CT. Higher level of T. spiralis-specific IgG2a was found than $T$. spiralis-specific IgG1, indicating that the IgG2a response was dominant (Fig. 3c, d; IgG1: $\chi^{2}=6.4889, d f=2, P=0.039 ; \operatorname{IgG} 2 \mathrm{a}: \chi^{2}=7.2$, $d f=2, P=0.0273)$. Although the IgG2a antibody response was dominant, $T$. spiralis-specific IgG1 antibody was also observed (Fig. 3c), indicating that T653K VLPs vaccination elicited Th1/Th2 mixed immune responses (Fig. 3c, d).

\section{Trichinella spiralis-specific antibody response after} challenge infection

To determine antibody response profiles in serum upon challenge infections, groups of mice were orally challenge infected with $T$. spiralis Korean isolate at week 4 after boost. To better understand the protective immune responses induced by $\mathrm{T} 653 \mathrm{~K}$ VLPs vaccination after challenge infection, T. spiralis-specific IgG, IgG1 and IgG2a were determined in the sera at weeks 1,4 and 6 after challenge infection (Fig. 4a, b, c). IgG, IgG1 and IgG2a antibody isotypes were significantly increased in groups of mice that received vaccination compared to those in TS control mice $(P<0.05$ and $P<0.01$, a

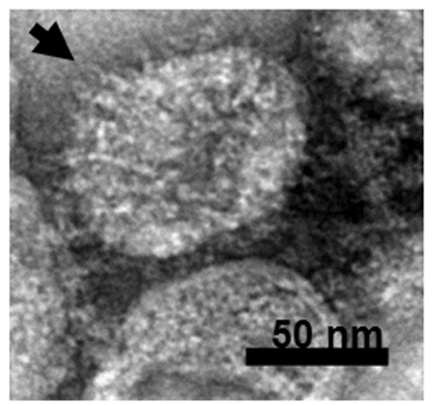

b

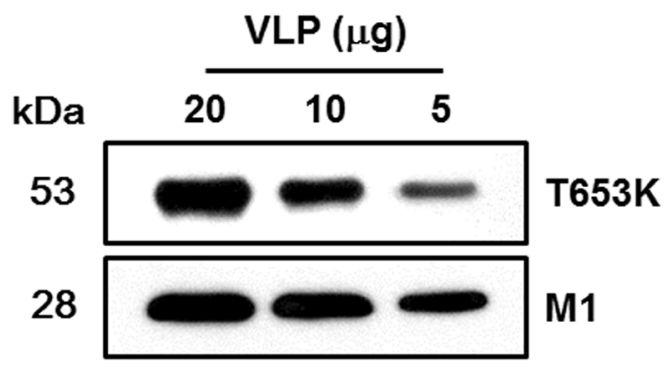

Fig. 2 Characterization of virus-like particles (VLPS). Electron microscopy and VLP size determination. Negative staining of VLPs was performed followed by transmission electron microscopy (TEM). The size is between 40 and $120 \mathrm{~nm}$ (a). Western blot analysis. VLPs (20, 10, $5 \mu \mathrm{g})$ were loaded for SDS-PAGE. Polyclonal mouse anti-T. spiralis antibody was used to probe T653k protein and anti-M1 monoclonal antibody was used to determine $\mathrm{M} 1$ protein $(\mathbf{b})$ 


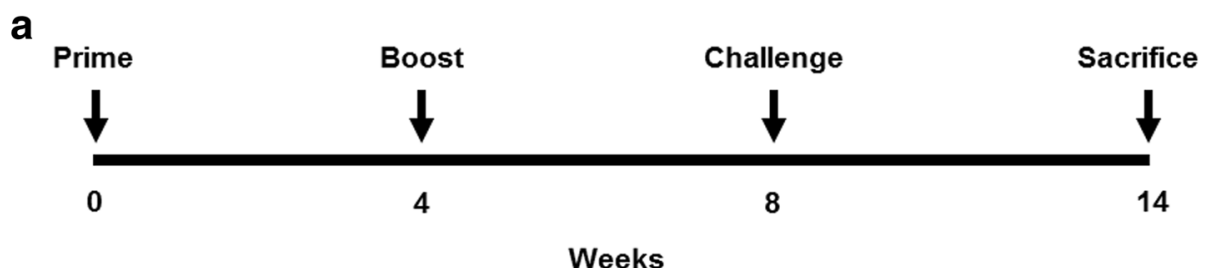

b

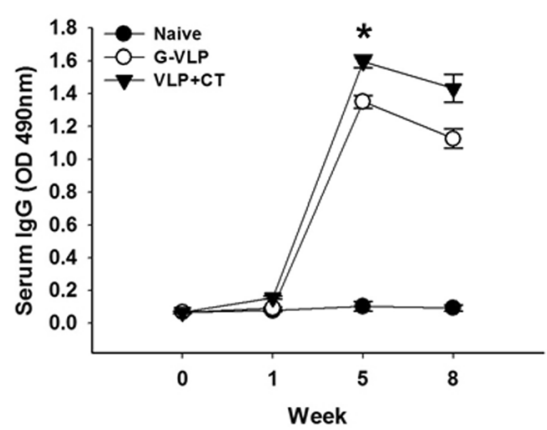

C

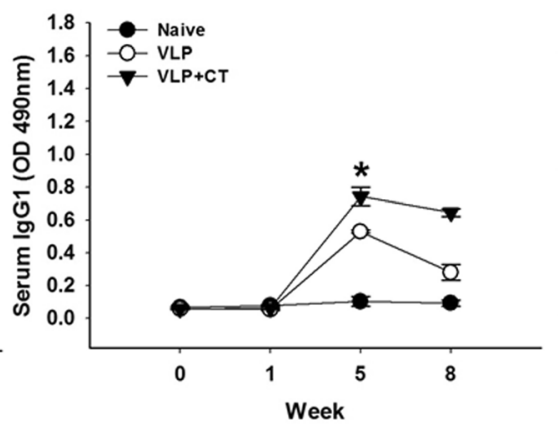

d

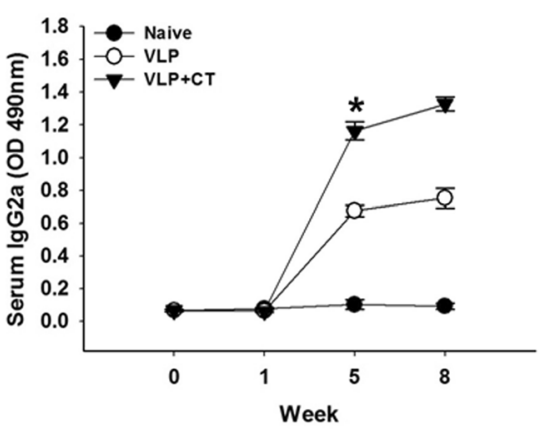

Fig. 3 Experimental schedule and T. spiralis-specific lgG subtype (IgG1 and lgG2a) responses upon immunization. Mice were immunized twice with VLPs as indicated with a 4-week interval. Challenge infection was performed at week 4 after last immunization (a). Enzyme-linked immunosorbent assay (ELISA) plates were coated with T. spiralis antigen, as indicated in Methods. T. spiralis-specific lgG, IgG1 and lgG2a antibody responses in the sera were determined after prime and boost. Significant differences were found between group VLPs alone and group VLP with cholera toxin (CT) (b, $\mathbf{c}$ and $\left.\mathbf{d},{ }^{*} P<0.05\right)$
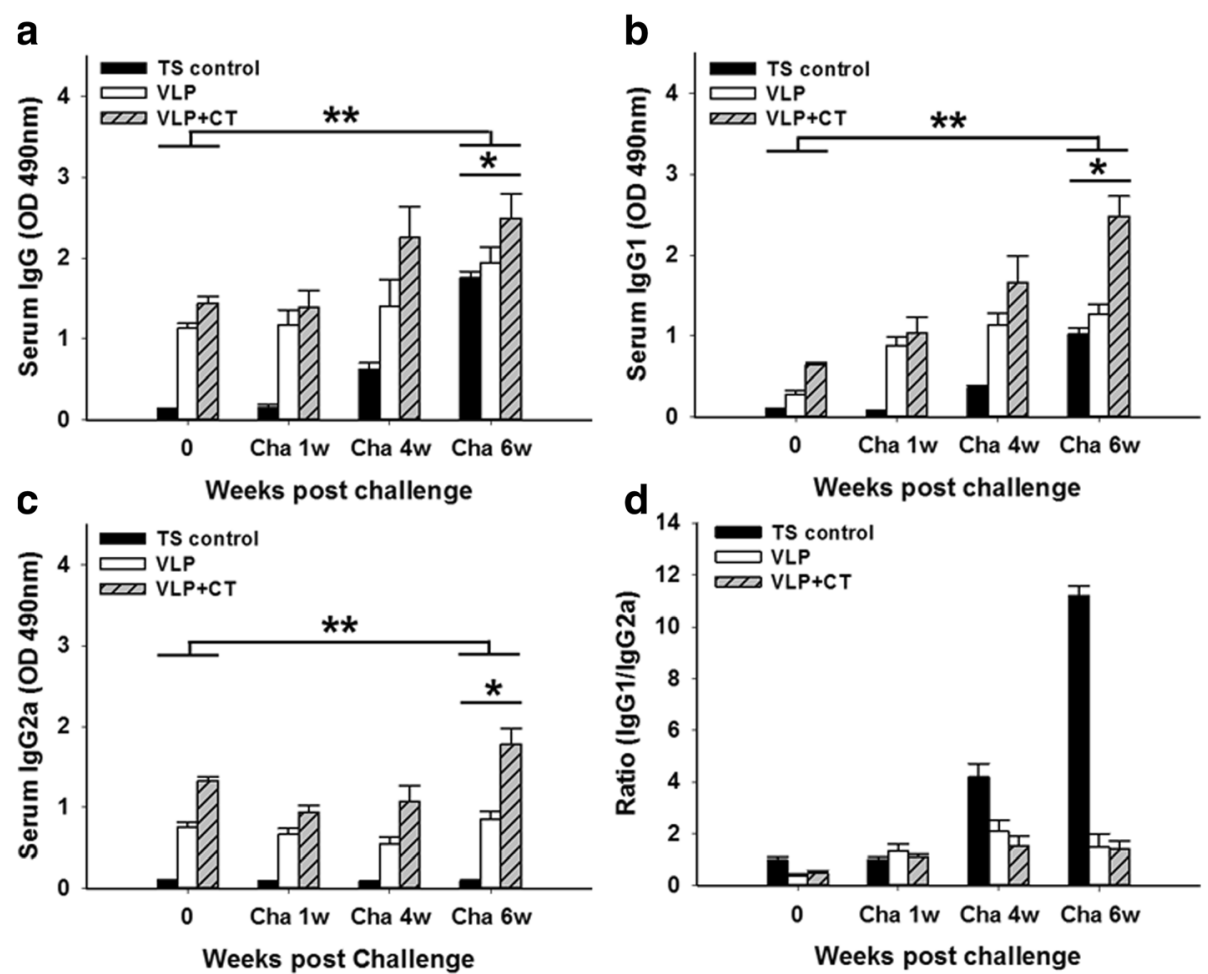

Fig. 4 Trichinella spiralis-specific antibody responses upon challenge infection. Immunized mice were challenge-infected orally with T. spiralis Korean isotype at week 4 after boost and T. spiralis-specific $\lg G, \lg G 1$ and $\lg G 2 \mathrm{a}$ antibody responses $\left(\mathbf{a}, \mathbf{b}\right.$ and $\left.\mathbf{c},{ }^{*} P<0.05 ;{ }^{*} P<0.01\right)$ and the ratio of $\lg G 1$ to $\lg G 2 \mathrm{a}$ in the sera were determined (d) 
respectively), in which VLPs vaccination with CT showed higher IgG, IgG1 and IgG2a responses. Significant differences in IgG, IgG1 and IgG2a levels among groups at week 6 post-challenge were found (IgG: $\chi^{2}=7.2, d f=2$, $P=0.0273$; IgG1: $\chi^{2}=7.2, d f=2, P=0.0273$; IgG2a: $\chi^{2}=$ 6.4889, $d f=2, P=0.039$ ). Significant differences between before and after challenges (week 6 post-challenge) were as follows: IgG: TS control: $t_{(44)}=39.99, P=0.0006$; VLP: $t_{(44)}=16.95, \quad \mathrm{P}=0.0035 ; \quad \mathrm{VLP}+\mathrm{CT}: \quad t_{(44)}=27.97, \quad P=$ 0.0013; IgG1: TS control: $t_{(44)}=25.7, P=0.0015$; VLP: $t_{(44)}=21.49, \quad P=0.0022 ; \quad$ VLP + CT: $\quad t_{(44)}=14.25, \quad P=$ 0.0049, and IgG2a: TS control: $t_{(44)}=1.08, P=0.3922$; VLP: $t_{(44)}=5.48, P=0.0317 ; \mathrm{VLP}+\mathrm{CT}: t_{(44)}=5.09, P=$ 0.0364. Importantly, IgG, IgG1 and IgG2a antibody levels were also found to be significantly higher in sera post-challenge than those before challenge, indicating the establishment of infection of larvae in the muscle that induces higher immune response. Especially, IgG on week 4 and 6 , IgG1 on week 1,4 and 6 , and IgG2a on week 6 were found to be significantly higher (Fig. 4a, b, c). The VLPs with CT adjuvant showed increased antibody responses compared to that without CT. Interestingly, upon challenge, mice immunized with T653k VLPs with CT showed IgG1-dominant responses (Fig. 4d). This suggests that vaccination with T653K VLPs with CT elicited an IgG1-dominant Th1/Th2mixed immune responses.

\section{Protective immunity}

To determine the efficacies of T653K VLP vaccine, groups of mice including naïve control and vaccinated mice were challenged with 100 larvae of $T$. spiralis at week 8 after vaccination. Mice were sacrificed at week 6 post-challenge and larvae were collected from the diaphragm (Fig. 3a). As shown in Fig. 5, the mice

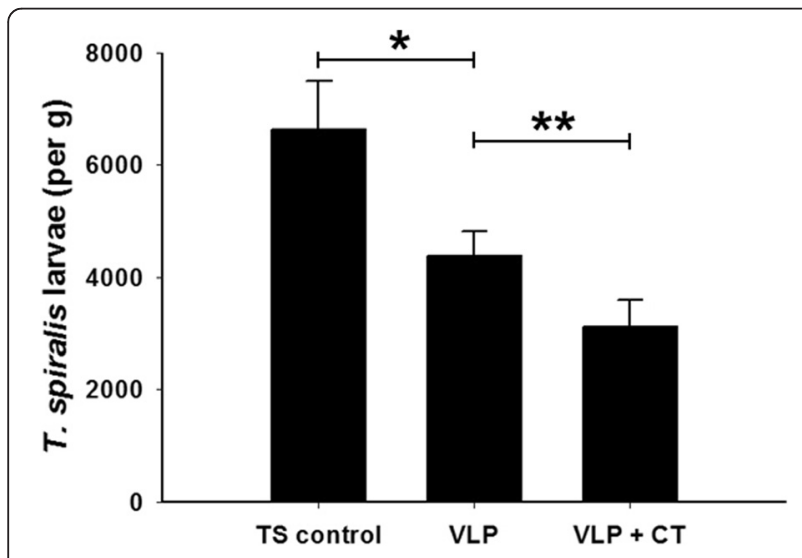

Fig. 5 Protection induced by vaccination. The larvae (per gram) from diaphragm were recovered from vaccinated mice after oral challenge infection with 100 T. spiralis larvae. Asterisks indicate statistically significant differences $\left({ }^{*} P<0.05\right.$; $\left.{ }^{* *} P<0.01\right)$ in worm recovery of the immunized groups compared to TS control group immunized with T653K VLPs with CT showed $53.2 \%$ of larval reduction, and the mice immunized with $\mathrm{T} 653 \mathrm{~K}$ VLPs showed $34 \%$ of worm reduction, respectively (Fig. 5, $t_{(44)}=4.46, P=0.021$ and $t_{(44)}=3.29, P=0.0462$, respectively). The results demonstrated that the intramuscular immunization with T653K VLPs vaccine induced partial protection against challenge infection with T. spiralis Korean isolate larvae, and VLPs with adjuvant $\mathrm{CT}$ showed better protection.

\section{Cytokine responses}

The levels of IFN- $\gamma$, IL-2, IL-4 and IL-10 from cytokinesecreting cells after immunization were determined as indicated in Fig. 6. Significantly higher levels of IFN- $\gamma$ $\left(\chi^{2}=8.9091, d f=2, P=0.0116\right), \mathrm{IL}-2\left(\chi^{2}=9.8462, d f=2\right.$, $P=0.0073)$, IL-4 $\left(\chi^{2}=8.0563, d f=2, P=0.0178\right)$ and IL$10\left(\chi^{2}=8.4049, d f=2, P=0.0150\right)$ cytokines were produced in VLP + CT and VLP groups following T. spiralis antigen stimulation compared to naïve controls, in which VLP + CT showed higher levels of cytokines compared to a VLP alone group. Since higher levels of Th1/ Th2-like cytokines were found in VLP or VLP + CT groups, we concluded that Th1/Th2-mixed type of immune responses was induced (Fig. 6; $P<0.05$ ).

\section{Discussion}

A VLP-induced protective immune response is different from DNA vaccine or protein vaccine. VLP vaccines are genetically engineered and produced in cell cultures. VLP vaccines contain multiple copies of protein antigens, inducing strong humoral and cellular immune responses [12]. DNA vaccines present endogenously expressed antigens to the immune systems, showing relatively low immunogenicity [23]. Recombinant protein vaccines consist of protein antigens produced in heterologous expression systems, inducing antibody response. Compared to VLP vaccines, DNA vaccine mainly induces cellular immunity. F DNA vaccine derived from respiratory syncytial virus (RSV) was not able to induce detectable levels of antibody responses [23]. Compared to VLP vaccines, recombinant H5 HA vaccine is less immunogenic, and vaccination even with 5-fold higher dose did not induce protective immunity [24]. Overall, VLPs offer many advantages in safety, immunogenicity and antigen stability. Taken together, VLP vaccines are promising vaccine candidates against different pathogens.

Virus-like particles (VLPs) represent one of the most exciting new vaccine technologies. VLPs do not contain any viral genetic material, and they have significant potential to elicit a strong immune response, without doing any actual harm $[25,26]$. The early vaccines (live, inactivated, subunit) are no longer considered as the most appropriate for new vaccine development [26]. Thus in our current study, for the first time, we used baculovirus 


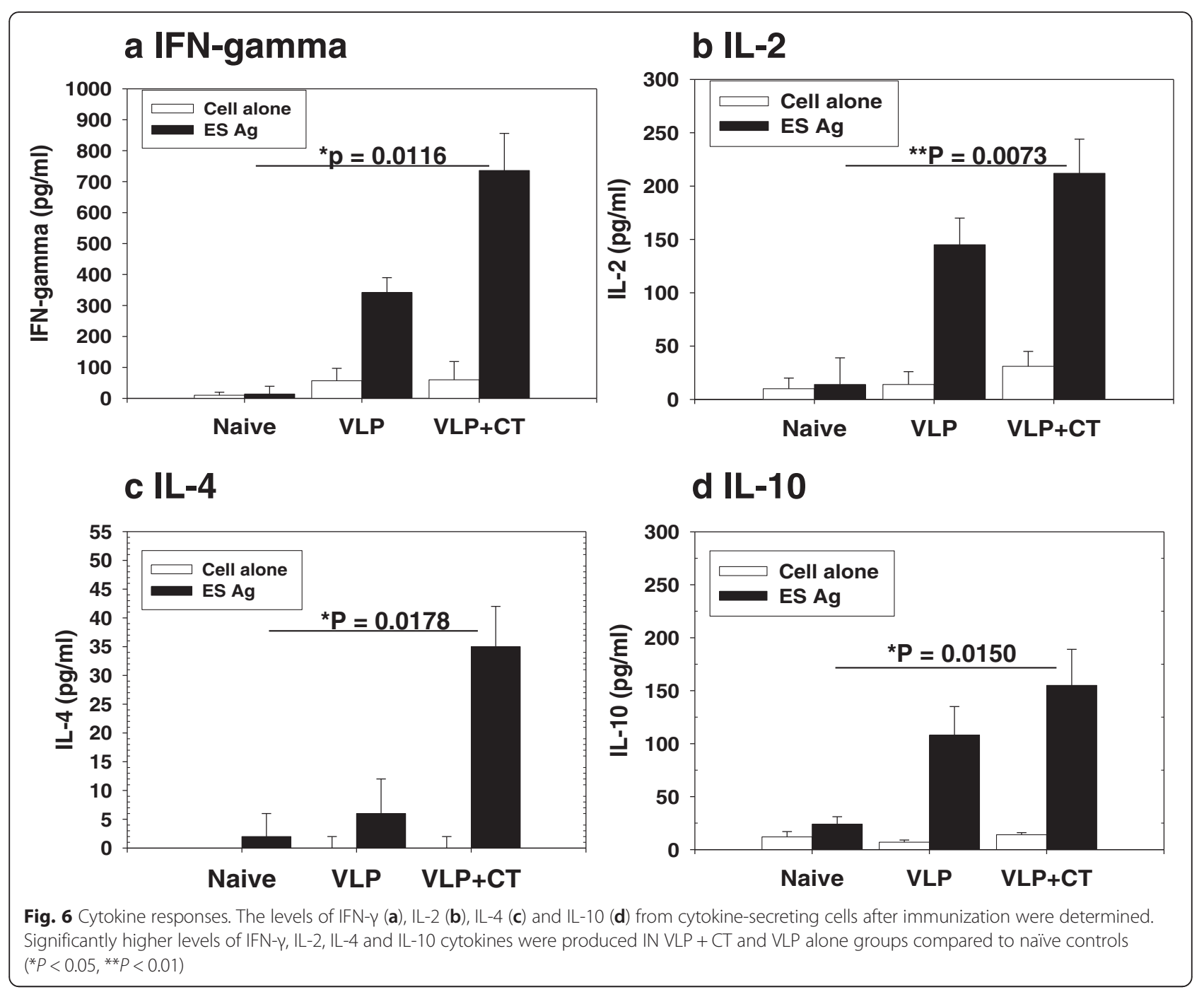

expression/VLP technology in a parasite nematode to produce parasite VLPs containing T. spiralis T653K and influenza M1 proteins. Our findings provide evidence that T653K VLPs with cholera toxin (CT) or without $\mathrm{CT}$ can induce protective immunity against live $T$. spiralis larval infection. The adjuvanted VLPs vaccine significantly improved humoral responses and protection upon challenge infection compared to VLPs alone.

Trichinella spiralis excretory-secretory (ES) protein has been demonstrated to induce protective immunity against $T$. spiralis infection. Immunization with $T$. spiralis ES protein elicited T. spiralis-specific IgG, IgG1 and IgG2a antibody responses [16]. Vaccination with ES protein microencapsulated in methacrylic acid copolymers elevated the antigen-specific serum IgG1 and IgA antibody responses, inducing Th1/Th2 immune responses that are protective [27]. Recombinant TspSP-1.2 protein derived from $T$. spiralis serine protease gene and Ts-ES$1(20 \mathrm{kDa})$ secreted by $T$. spiralis induced partial protections, considering it is a potential candidate for vaccine development against $T$. spiralis infection [28, 29]. These recombinant proteins were produced from an E. coli expression system, and vaccine efficacy was not successful. In the current study, we used T653K derived from T. spiralis ES Ag $53 \mathrm{kDa}$ as a surface protein of VLPs, for which vaccine efficacy has not been studied previously. Our study indicated that vaccination with $T$. spiralis T653K containing VLPs elicited T. spiralis-specific IgG, IgG1 and IgG2a antibody responses and partial protection against $T$. spiralis challenge in mice.

Results shown in the present study indicate that the pattern of IgG1 and IgG2a immune responses is affected by challenge infection. T653K VLPs vaccination induced higher level of $T$. spiralis-specific IgG2a antibodies before challenge and subsequent challenge infection significantly increased the levels of IgG1 antibodies (Figs. 3, 4). An effective vaccine must direct Thelper cells toward the development of Th1, rather 
than Th2 responses. Moreover, a humoral response is necessary because specific antibodies limit the multiplication of parasite by killing extracellular parasite, either by activating the complement system or by opsonizing the parasites for phagocytosis and macrophage killing [30-32]. Importantly, in the present study, IgG1 antibodies before challenge and IgG2a antibody after challenge infection were also induced, indicating a Th1/ Th2-mixed type of immune response, which is important for protective immunity against $T$. spiralis infection $[33,34]$. Induction of IgG1 antibody responses upon challenge might be necessary since parasite-specific antibodies and the associated Th2 responses have been reported to limit worm establishment and may even play a role in diminishing the effect of challenge infections [35]. Further studies are needed for better understanding of the immune mechanisms affecting the pattern of antibody isotypes induced by vaccination.

Cholera toxin (CT) is known to be a potent adjuvant. CT can induce maturation of dendritic cells and augment the priming of $\mathrm{CD}_{4}^{+} \mathrm{T}$ cells and the antigen presentation by dendritic cells and B cells [36-39]. However, the role of CT adjuvant in parasite vaccine fields is unknown. In the present study, for the first time, we investigated protective efficacy in mice immunized with VLPs alone or with CT-adjuvanted VLPs. Cholera toxin (CT) has been widely shown to be effective as a potent mucosal vaccine adjuvant. There is a strong supporting report, in which cholera toxin by nonconventional adjuvant pathway induces protective memory responses after epicutaneous vaccination [40]. In the present study, mice intramuscularly immunized with CT-adjuvanted VLPs showed significantly enhanced T653K VLP-induced $T$. spiralis-specific immune response. All immunized mice were partially protected against challenge infection with $T$. spiralis, in which mice immunized with CTadjuvanted VLPs showed significant decrease in worm burden compared to mice immunized with VLPs alone (Fig. 5), indicating that the adjuvant plays an important role in enhancing the protective efficacy. Mice immunized with CT-adjuvanted VLPs showed significantly improved protection, indicating the use of a safe and effective adjuvant would have a significant impact for developing VLP vaccines. Since a careful selection of adjuvant is important depending on specific vaccine antigens and desired types of protective immunity, further studies are needed for better understanding of the immune mechanisms induced by adjuvants [41].

\section{Conclusions}

Overall, the present studies provide new insight into $T$. spiralis VLPs-induced protective efficacy. Intramuscular immunization with VLPs alone or with CT elicited a systemic Th1/Th2-mixed type of immune response and produced a partial protection against $T$. spiralis infection in mice. CT-adjuvanted VLPs showed significantly increased immunogenicity.

\section{Additional file}

\begin{abstract}
Additional file 1: Figure S1. Trichinella spiralis ES product was separated by sodium dodecyl sulphate-polyacrylamide gel electrophoresis (SDS-PAGE) in $12 \%$ polyacrylamide gels using a Mini-PROTEAN Tetra Cell electrophoresis unit (Bio-Rad, USA). Trichinella spiralis ES product $(40,20,10,5 \mu \mathrm{g})$ was loaded and incubated at $150 \mathrm{~V}$ for $1 \mathrm{~h}$. To determine the proteins in $T$. spiralis ES product, the gel was stained with coomassie blue. Trichinella spiralis T653k protein was detected in T. spiralis ES product. (PDF 45 KB)
\end{abstract}

\section{Abbreviations}

$C T$, cholera toxin; ELISA, enzyme-linked immunosorbent assay; ES, excretory/ secretory; HRP, Horseradish peroxidase; PBS, phosphate-buffered saline; SD', Sprague-Dawley; SDS-PAGE, sodium dodecyl sulphate-polyacrylamide gel electrophoresis; VLP, virus-like particle

\section{Acknowledgements}

We thank Dr. Compans W. Richard for providing great help in improving manuscript.

\section{Funding}

This work was supported by a grant from the National Research Foundation of Korea (NRF) (NRF-2014R1A2A2A01004899), a grant from the Agri-Bio Industry Technology Development Program (315030-03-1-HD020), IPET, MAFRA, $\mathrm{KHIDI}$, and a grant from the Ministry of Health and Welfare, Republic of Korea (H15C2928).

\section{Availability of data and materials}

Data supporting the conclusions of this article are included within the article.

\section{Authors' contributions}

$\mathrm{SH}$ carried out the molecular genetic studies, participated in the sequence alignment, prepared VLPS and drafted the manuscript. SS carried out analysis and interpretation of data. DH and AR carried out animal experiment. FQ carried out the experiment design, analysis and interpretation of data and drafted the manuscript. All authors read and approved the final version of the manuscript

\section{Competing interests}

The authors declare that they have no competing interests.

\section{Consent for publication}

Not applicable.

\section{Ethics approval}

All animal experiments and husbandry involved in these studies were conducted under the guidelines of the Kyung Hee University IACUC. Kyung Hee IACUC operates under the National Veterinary Research and Quarantine Service (NVRQS) and regulations of the World Organization for Animal Health (WOAH).

\section{Author details}

${ }^{1}$ Department of Biomedical Science, Graduate School, Kyung Hee University, Seoul, South Korea. '2Department of Medical Zoology, Kyung Hee University School of Medicine, Seoul, South Korea.

Received: 3 March 2016 Accepted: 22 June 2016

Published online: 04 July 2016

\section{References}

1. Murrell KD, Pozio E. Worldwide occurrence and impact of human trichinellosis, 1986-2009. Emerging Infect Dis. 2011;17(12):2194-202.

2. Kurdova-Mintcheva $R$, Jordanova D, Ivanova M. Human trichinellosis in Bulgaria - epidemiological situation and trends. Vet Parasitol. 2009;159(3):316-9. 
3. Ribicich M, Gamble H, Bolpe J, Scialfa E, Krivokapich S, Cardillo N, et al. Trichinella infection in wild animals from endemic regions of Argentina. Parasitol Res. 2010;107(2):377-80.

4. Kim G, Choi M, Kim J, Kang YM, Jeon HJ, Jung Y, et al. An outbreak of trichinellosis with detection of Trichinella larvae in leftover wild boar meat. J Korean Med Sci. 2011;26(12):1630-3.

5. Pompa-Mera E, Yépez-Mulia L, Ocana-Mondragon A, Garcia-Zepeda E, Ortega-Pierres G, Gonzalez-Bonilla C. Trichinella spiralis: intranasal immunization with attenuated Salmonella enterica carrying a gp43 antigenderived 30mer epitope elicits protection in BALB/c mice. Exp Parasitol. 2011; 129(4):393-401.

6. Wang Z, Cui J, Wei H, Han H, Zhang H, Li Y. Vaccination of mice with DNA vaccine induces the immune response and partial protection against $T$. spiralis infection. Vaccine. 2006;24(8):1205-12.

7. Fang L, Sun L, Yang J, Gu Y, Zhan B, Huang J, et al. Heat shock protein 70 from Trichinella spiralis induces protective immunity in BALB/C mice by activating dendritic cells. Vaccine. 2014;32(35):4412-9.

8. Liu X, Wang X, Bai X, Liu X, Wu X, Zhao Y, et al. Oral administration with attenuated Salmonella encoding a Trichinella cystatin-like protein elicited host immunity. Exp Parasitol. 2014;141:1-11.

9. Gu Y, Li J, Zhu X, Yang J, Li Q, Liu Z, et al. Trichinella spiralis: characterization of phage-displayed specific epitopes and their protective immunity in BALB/c mice. Exp Parasitol. 2008;118(1):66-74.

10. McGuire C, Chan WC, Wakelin D. Nasal immunization with homogenate and peptide antigens induces protective immunity against Trichinella spiralis. Infect Immun. 2002;70(12):7149-52.

11. Liu P, Chi J, Liu RD, Wang M, Jiang P, Liu LN, Long SR, Li LG, Zhang SB, Zhang $X Z$, Wang ZQ. Protective immunity aginst Trichinella spiralis infection induced by TsNd vaccine in mice. Parasit Vectors. 2015;28(8):185-195.

12. Akahata W, Yang Z, Andersen H, Sun S, Holdaway HA, Kong W, et al. A virus-like particle vaccine for epidemic Chikungunya virus protects nonhuman primates against infection. Nat Med. 2010;16(3):334-8.

13. Adolph KW, Butler PJ. Assembly of a spherical plant virus. Philos Trans R Soc Lond B Biol Sci. 1976;276(943):113-22.

14. Ding Y, Chuan YP, He L, Middelberg AP. Modeling the competition between aggregation and self-assembly during virus-like particle processing. Biotechnol Bioeng. 2010;107(3):550-60.

15. Chromy LR, Pipas JM, Garcea RL. Chaperone-mediated in vitro assembly of Polyomavirus capsids. Proc Natl Acad Sci U S A. 2003;100(18):10477-82.

16. Quan F, Matsumoto T, Lee J, Timothy O, Lee J, Kim TS, et al. Immunization with Trichinella spiralis Korean isolate larval excretory-secretory antigen induces protection and lymphocyte subset changes in rats. Immunol Invest. 2004;33(1):15-26

17. Du L, Tang H, Ma Z, Xu J, Gao W, Chen J, et al. The protective effect of the recombinant 53-kDa protein of Trichinella spiralis on experimental colitis in mice. Dig Dis Sci. 2011;56(10):2810-7.

18. Wang L, Wang ZQ, Hu DD, Cui J. Proteomic analysis of Trichinella spiralis muscle larval excretory-secretory proteins recognized by early infection sera. Biomed Res Int. 2013:2013:139745.

19. Nagano I, Wu Z, Takahashi Y. Species-specific antibody responses to the recombinant 53-kilodalton excretory and secretory proteins in mice infected with Trichinella spp. Clin Vaccine Immunol. 2008;15(3):468-73.

20. Goyal P, Bolas-Fernandez F, Wakelin D. Immunization of mice against Trichinella spiralis and T. britovi using excretory and secretory antigens. J Helminthol. 1997;71(02):109-12

21. Quan F, Matsumoto T, Shin Y, Min Y, Yang H, Othman T, et al. Relationships between $\operatorname{lgG}$, IgM, IgE and resistance to reinfection during the early phase of infection with Clonorchis sinensis in rats. Immunol Invest. 2004;33(1):51-60.

22. Robinson K, Bellaby T, Wakelin D. Immunity to Trichinella spiralis transferred by serum from vaccinated mice not protected by immunization. Parasite Immunol. 1995;17(2):85-90.

23. Lee JS, Kwon Y, Hwang HS, Lee Y, Ko E, Yoo S, et al. Baculovirus-expressed virus-like particle vaccine in combination with DNA encoding the fusion protein confers protection against respiratory syncytial virus. Vaccine. 2014 32(44):5866-74.

24. Song J, Hossain J, Yoo D, Lipatov AS, Davis CT, Quan F, et al. Protective immunity against $\mathrm{H} 5 \mathrm{~N} 1$ influenza virus by a single dose vaccination with virus-like particles. Virology. 2010;405(1):165-75.

25. Kang S, Song J, Quan F, Compans RW. Influenza vaccines based on virus-like particles. Virus Res. 2009:143(2):140-6.
26. Pitoiset F, Vazquez T, Bellier B. Enveloped virus-like particle platforms: vaccines of the future? Expert Rev Vaccines. 2015:14(7):913-5.

27. Dea-Ayuela MA, Rama-Iñiguez S, Bolas-Fernández F. Vaccination of mice against intestinal Trichinella spiralis infections by oral administration of antigens microencapsulated in methacrilic acid copolymers. Vaccine. 2006; 24(15):2772-80.

28. Wang B, Wang ZQ, Jin J, Ren HJ, Liu LN, Cui J. Cloning, expression and characterization of a Trichinella spiralis serine protease gene encoding a 35 . 5 kDa protein. Exp Parasitol. 2013;134(2):148-54.

29. Bi K, Yang J, Wang L, Gu Y, Zhan B, Zhu X. Partially protective immunity induced by a $20 \mathrm{kDa}$ protein secreted by Trichinella spiralis stichocytes. PloS one. 2015;10(8):e0136189.

30. Johnson LL, Sayles PC. Deficient humoral responses underlie susceptibility to Toxoplasma gondii in CD4-deficient mice. Infect Immun. 2002;70(1):185-91.

31. Kang H, Remington JS, Suzuki Y. Decreased resistance of B cell-deficient mice to infection with Toxoplasma gondii despite unimpaired expression of IFN-gamma, TNF-alpha, and inducible nitric oxide synthase. J Immunol. 2000;164(5):2629-34

32. Vercammen M, Scorza T, Bouhdidi A, Beeck K, Carlier Y, Dubremetz JF, et al. Opsonization of Toxoplasma gondii tachyzoites with nonspecific immunoglobulins promotes their phagocytosis by macrophages and inhibits their proliferation in nonphagocytic cells in tissue culture. Parasite Immunol. 1999;21(11):555-63.

33. Yang Y, Zhang Z, Yang J, Chen X, Cui S, Zhu X. Oral vaccination with Ts87 DNA vaccine delivered by attenuated Salmonella typhimurium elicits a protective immune response against Trichinella spiralis larval challenge. Vaccine. 2010;28(15):2735-42.

34. Deville S, de Pooter A, Aucouturier J, Lainé-Prade V, Cote M, Boireau P, et al. Influence of adjuvant formulation on the induced protection of mice immunized with total soluble antigen of Trichinella spiralis. Vet Parasitol. 2005;132(1):75-80.

35. Blackwell NM, Else KJ. B cells and antibodies are required for resistance to the parasitic gastrointestinal nematode Trichuris muris. Infect Immun. 2001; 69(6):3860-8.

36. Gagliardi MC, Sallusto F, Marinaro M, Langenkamp A, Lanzavecchia A, De Magistris MT. Cholera toxin induces maturation of human dendritic cells and licences them for Th2 priming. Eur J Immunol. 2000;30(8):2394-403.

37. Lycke N. The mechanism of cholera toxin adjuvanticity. Res Immunol. 1997; 148(8):504-20.

38. Freytag L, Clements J. Mucosal adjuvants. Vaccine. 2005;23(15):1804-13.

39. Guebre-Xabier M, Hammond SA, Epperson DE, Yu J, Ellingsworth L, Glenn GM. Immunostimulant patch containing heat-labile enterotoxin from Escherichia coli enhances immune responses to injected influenza virus vaccine through activation of skin dendritic cells. J Virol. 2003;77(9):5218-25.

40. Olvera-Gomez I, Hamilton SE, Xiao Z, Guimaraes CP, Ploegh HL, Hogquist $K A$, et al. Cholera toxin activates nonconventional adjuvant pathways that induce protective CD8 T-cell responses after epicutaneous vaccination. Proc Natl Acad Sci USA. 2012;109(6):2072-7.

41. Quan F, Ko E, Kwon Y, Joo KH, Compans RW, Kang S. Mucosal adjuvants for influenza virus-like particle vaccine. Viral Immunol. 2013:26(6):385-95.

\section{Submit your next manuscript to BioMed Central and we will help you at every step:}

- We accept pre-submission inquiries

- Our selector tool helps you to find the most relevant journal

- We provide round the clock customer support

- Convenient online submission

- Thorough peer review

- Inclusion in PubMed and all major indexing services

- Maximum visibility for your research

Submit your manuscript at www.biomedcentral.com/submit 